\title{
conjunto residencial Monterinaldi
}

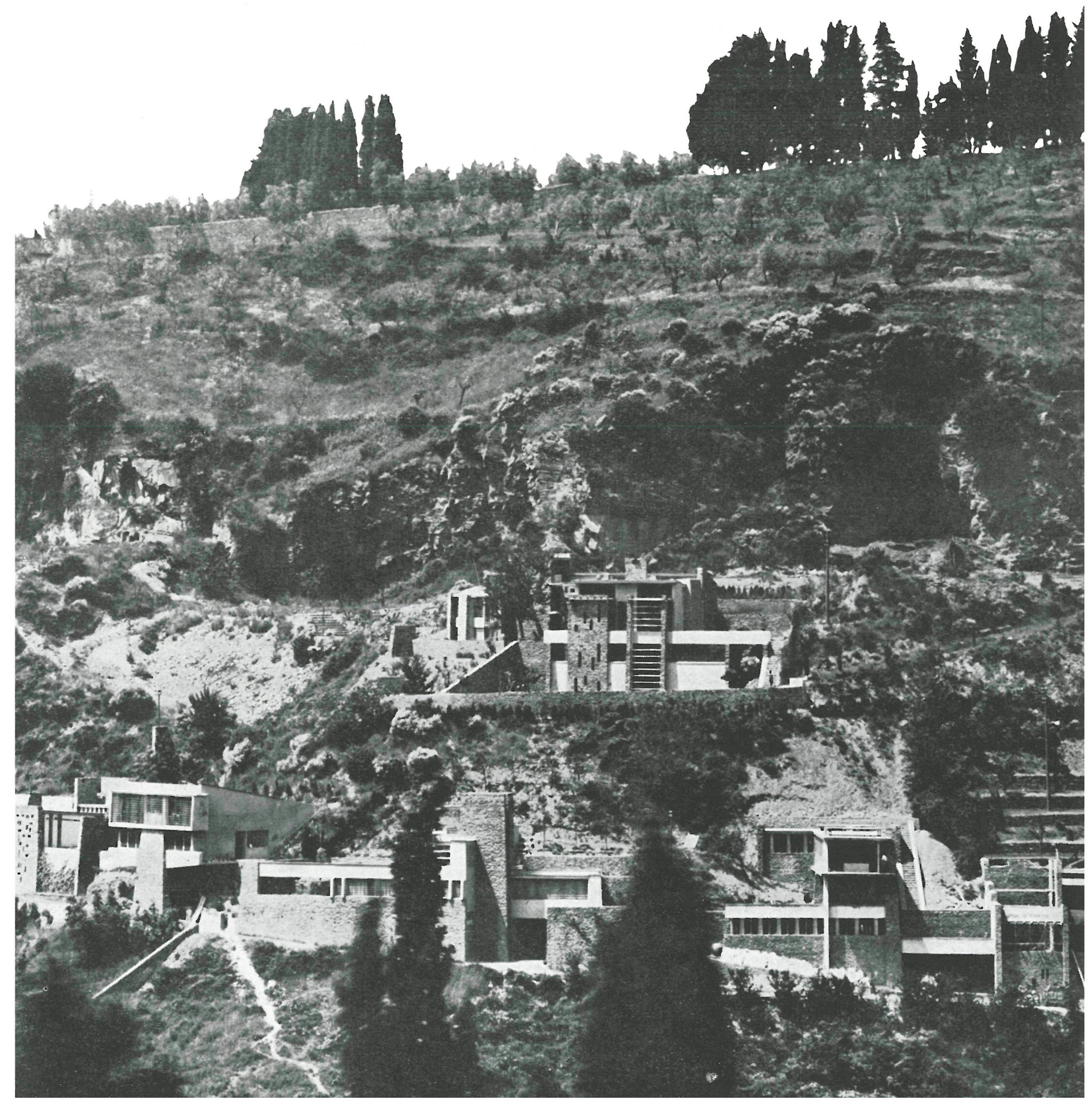


En una hermosa colina, situada a unos ocho kilómetros de Florencia, y con grandiosas vistas sobre la ciudad, se han distribuído un grupo de villas, con un criterio doble de uniformidad formal y mimetismo asombroso con la naturaleza circundante.

Las edificaciones se disponen a lo largo de dos cornisas
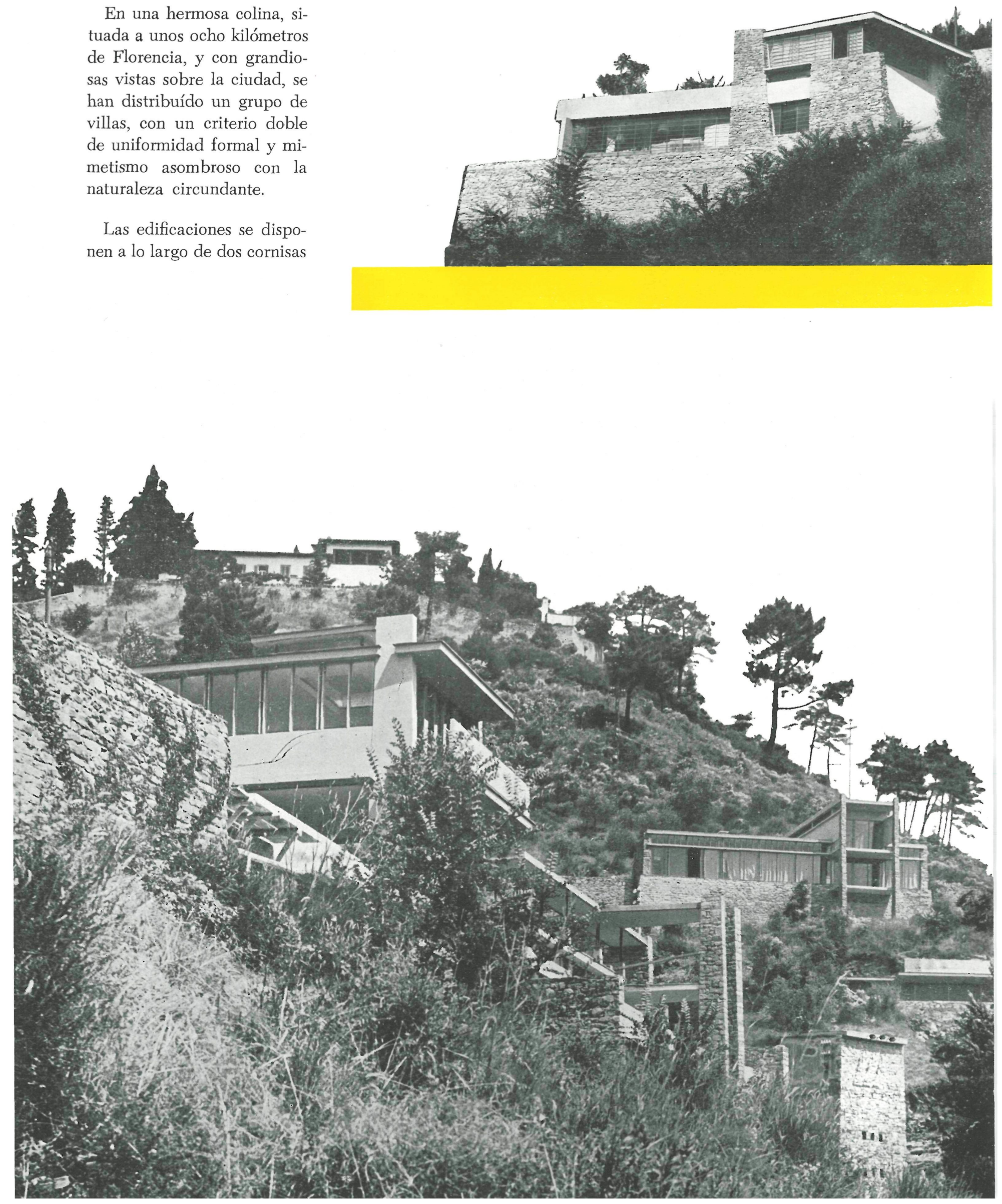


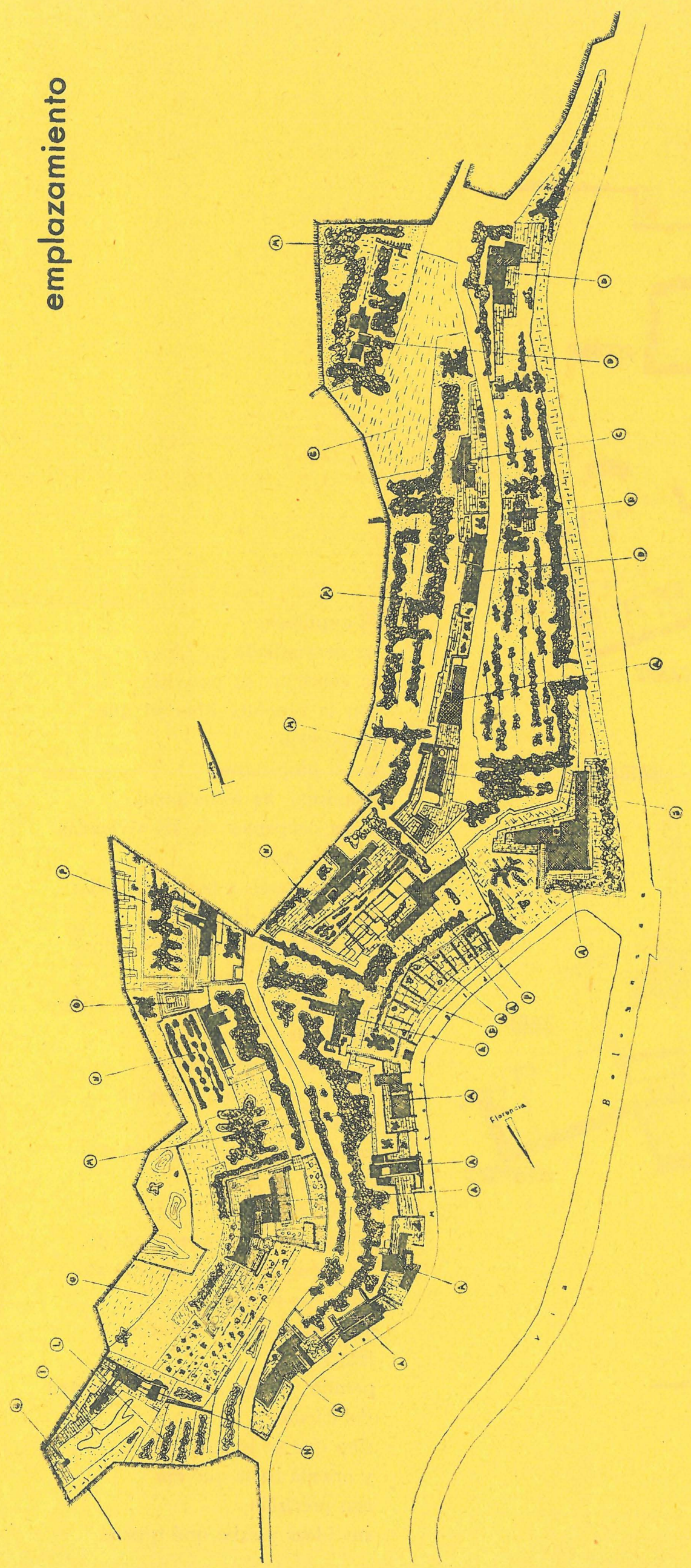

superpuestas,

alineándose según imperativo de las curvas de nivel,

al objeto de ceñirse

lo más cómodamente al terreno, permitir amplias vistas desde todos los puntos y realizar el menor movimiento de tierra posible,

a la vez que conseguir gratos desniveles en cada vivienda.

La colonia actual de recio y enérgico diseño, está compuesta por un crítico literario, dos químicos,

un escultor,

dos pintores, un ceramista,

un ingeniero, un agente de ventas, un tintorero,

una condesa, local comercial, restaurante,

piscina, estudios de alquiler...

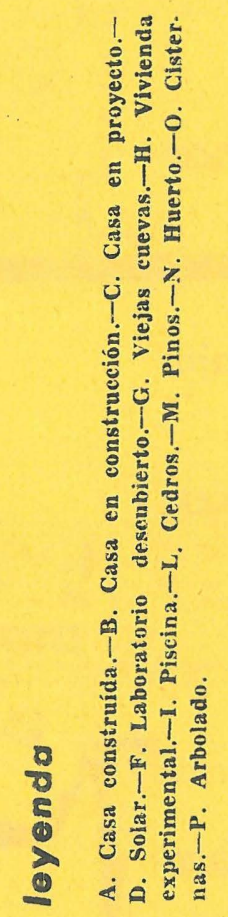




\section{casa RICCI}

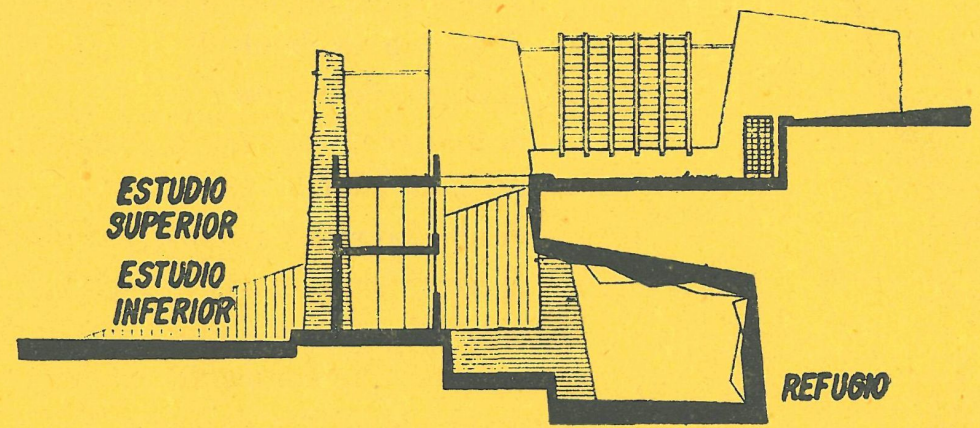

sección

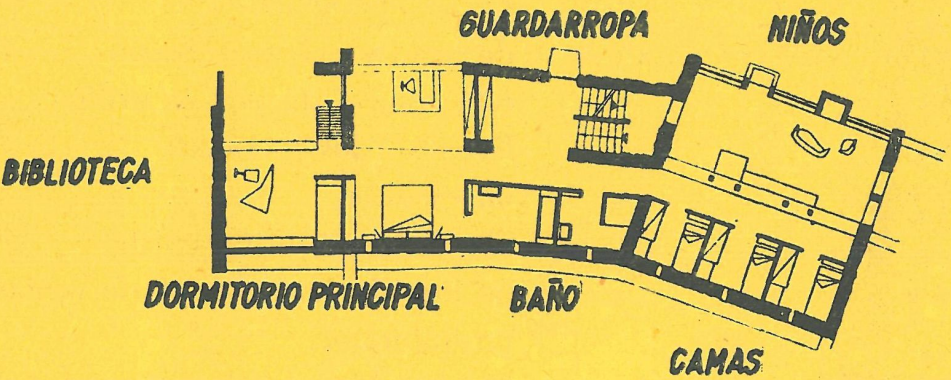

planta de semisótano
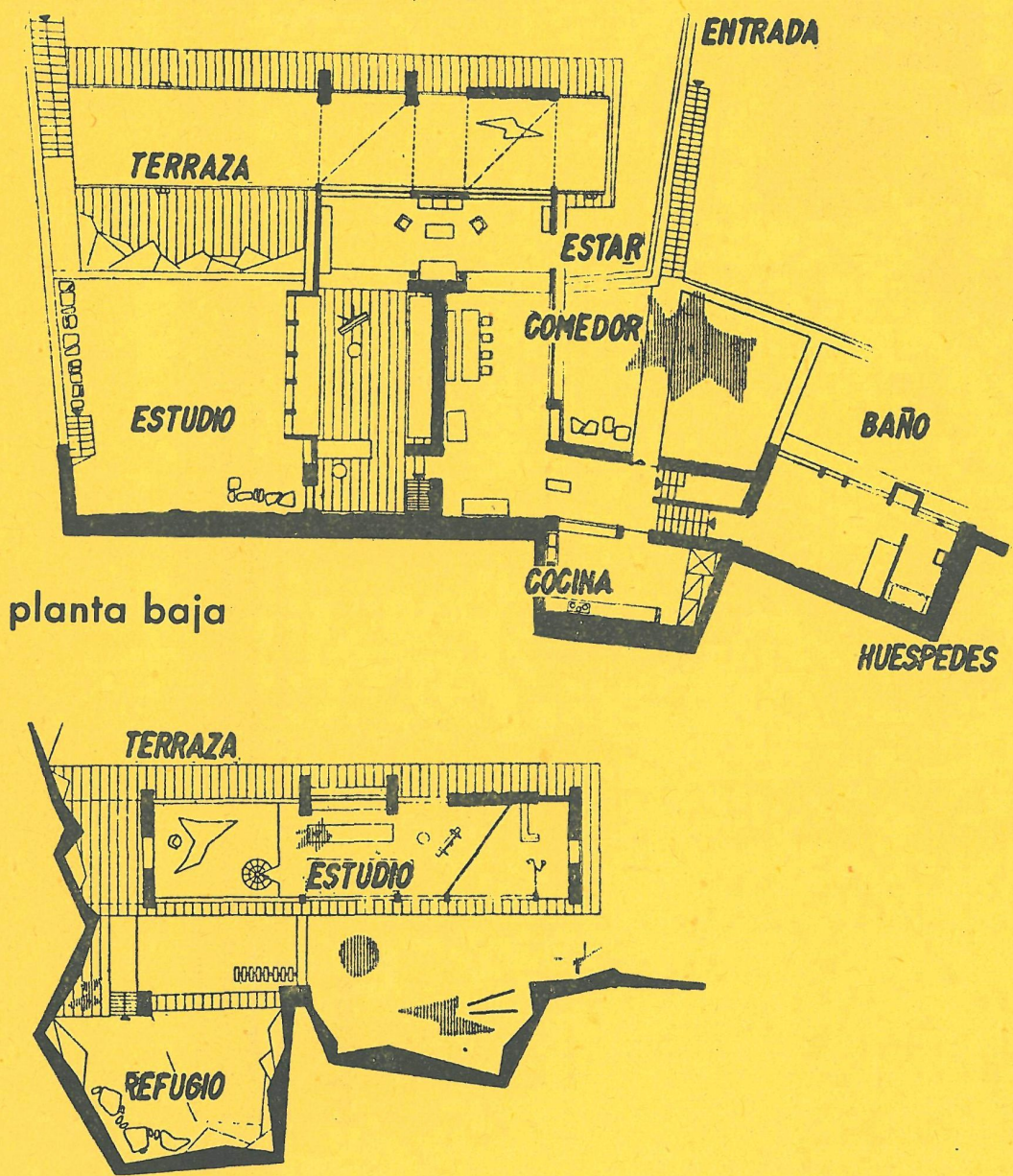

p'anta primera
El arquitecto

ha desarrollado su idea, su concepto, su proyecto, con la absoluta libertad que proporciona ser el propietario.

Asimismo, ha seleccionado a los ocupantes de las viviendas, para lo cual solía invitarles a pasar unos días en su propio hogar, compenetrándose así con ellos y haciéndoles gustar del lugar y de las casas que serían semejantes.

El primer paso consistía en que el cliente aceptase sin discusión la estructura y criterio estético exterior, lo que constituía la base de un primer contrato. La segunda parte del contrato, la que se refiere a la distribución y detalles interiores, permite, no sólo la absoluta libertad del cliente, sino que se le aconseja y orienta hasta que fija con precisión sus ideas y sabe qué quiere. 
cas a Ricci
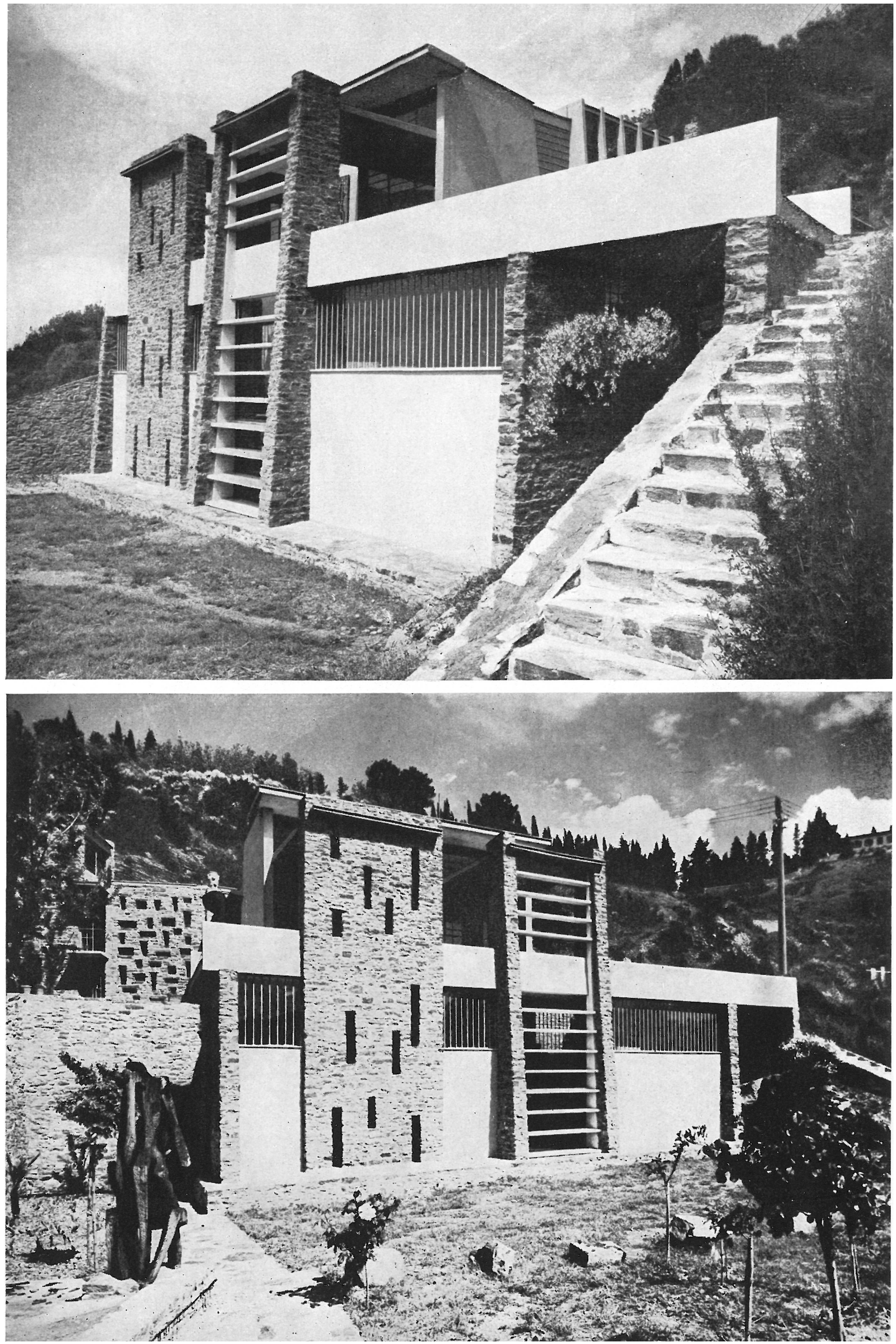


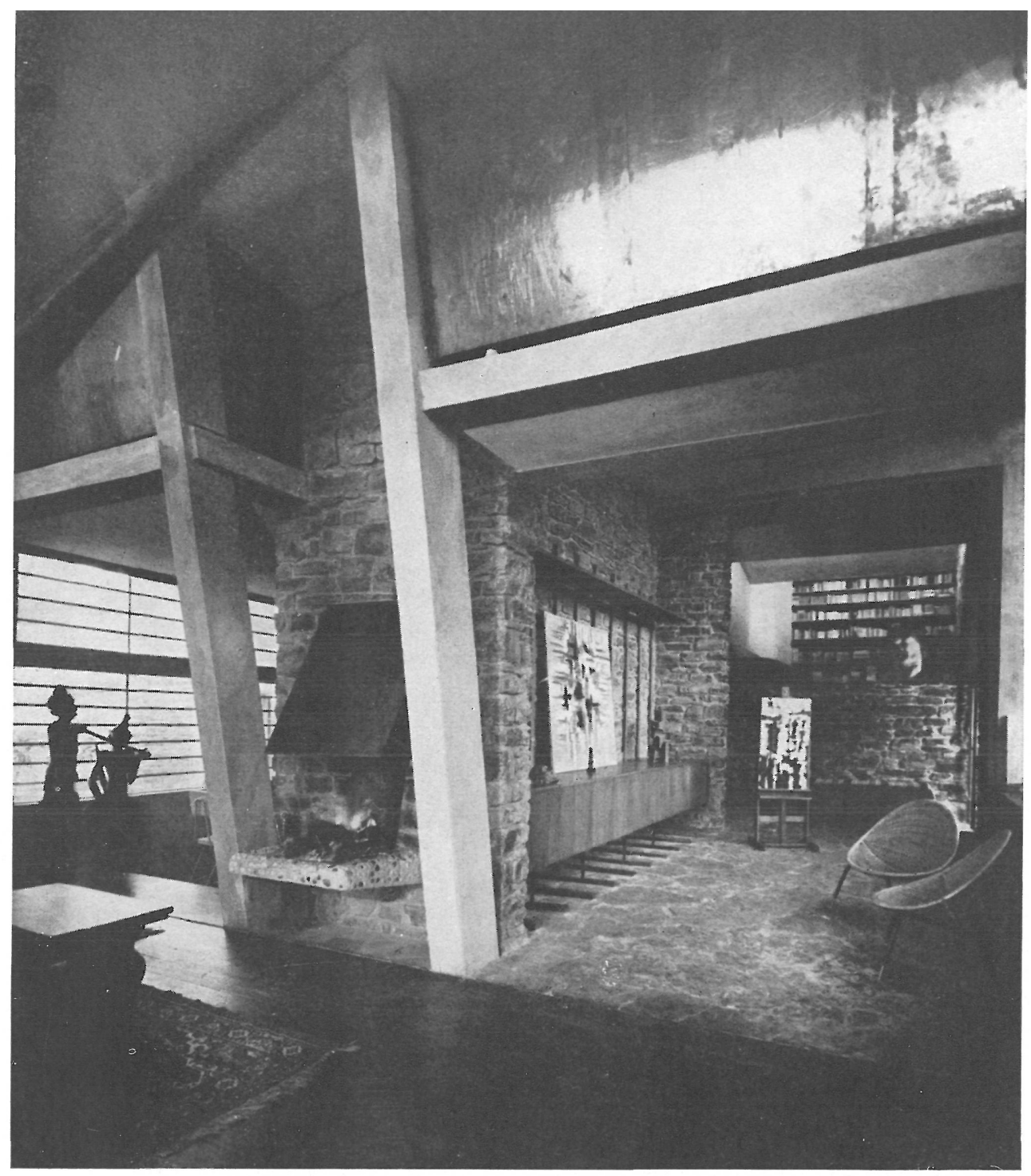

Los materiales empleados son básicos: piedra, hormigón, carpintería metálica y maderas. La piedra se ha utilizado con profusión, ya que procede de las excavaciones realizadas en el propio lugar, porque siempre presta nobleza y reciedumbre a los edificios y porque su color armoniza perfectamente con el del paisaje del que se ha extraído.

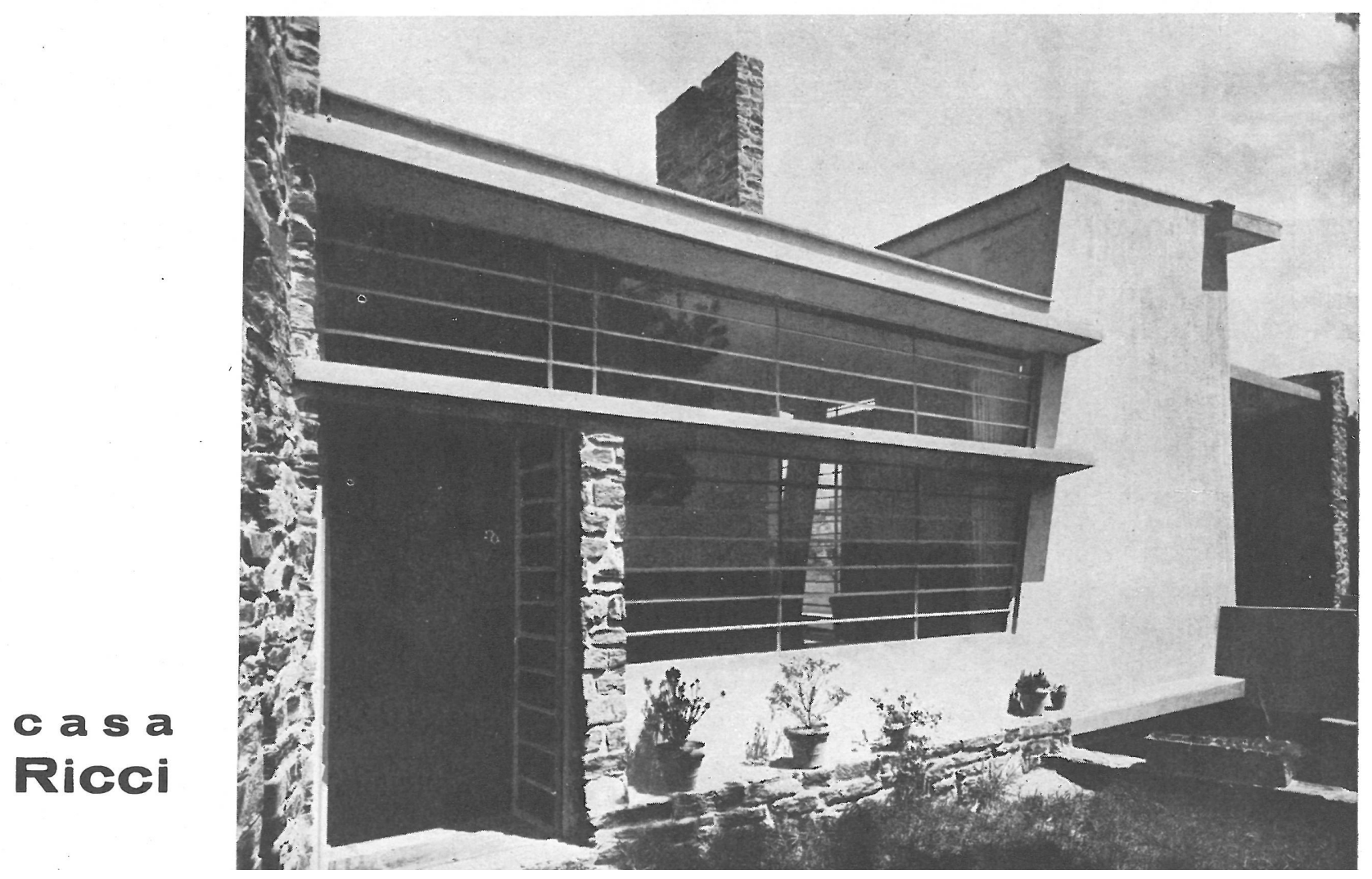



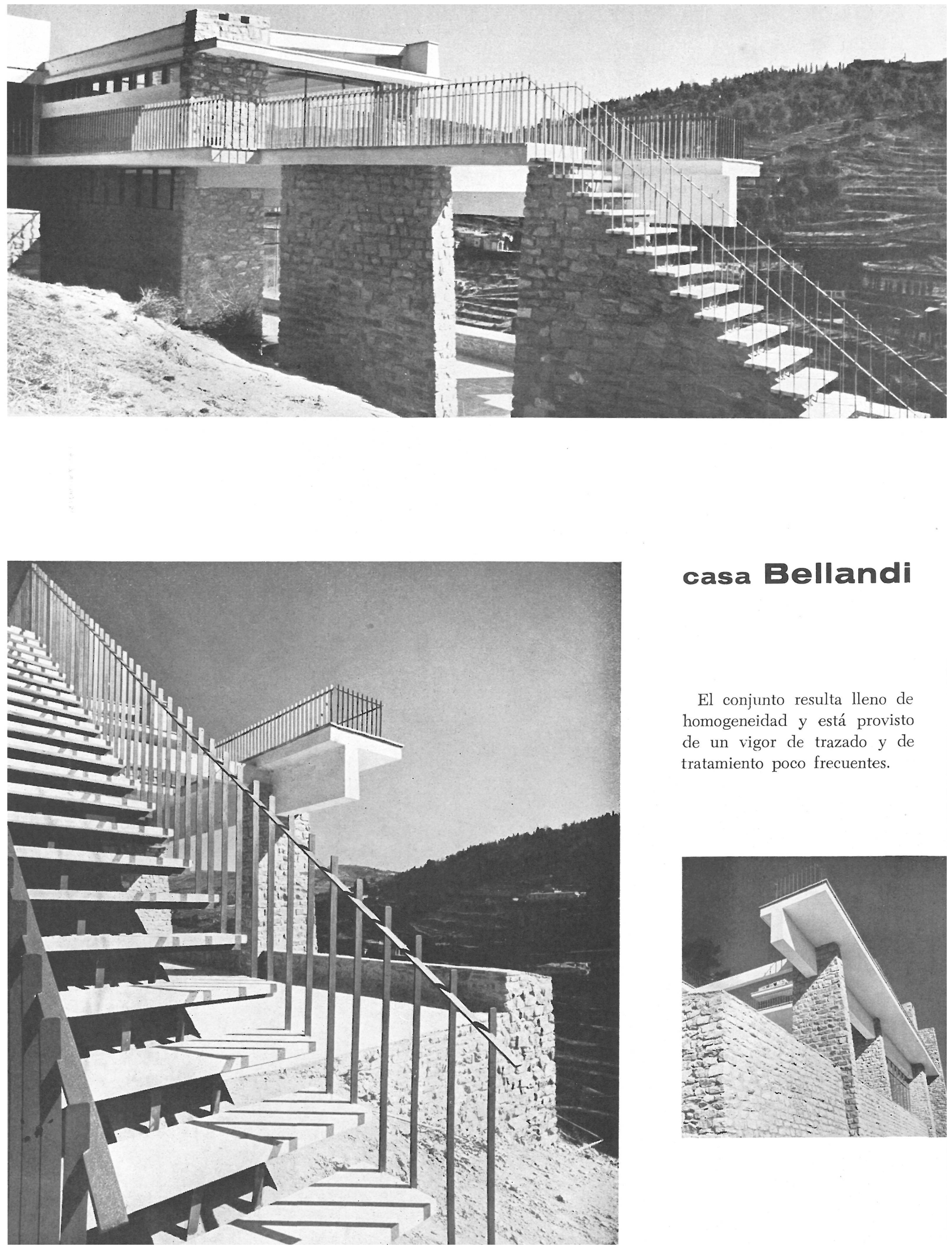

\section{casa Bellandi}

El conjunto resulta lleno de homogeneidad y está provisto de un vigor de trazado y de tratamiento poco frecuentes.

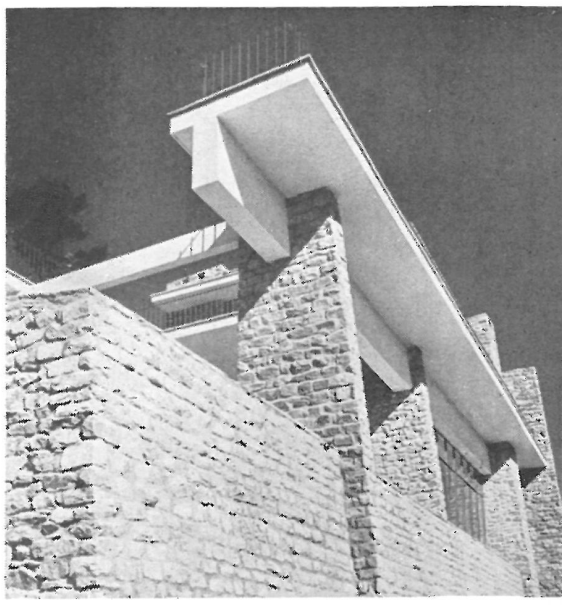




\section{casa Selleri}

Los grandes ventanales, abiertos hacia el horizonte, alternan con los muros de mampostería careada, de aspecto basto, y el imperio dominante de la línea recta imprime su sello y tranquilidad característicos.

\section{casa estudio Innocenti}
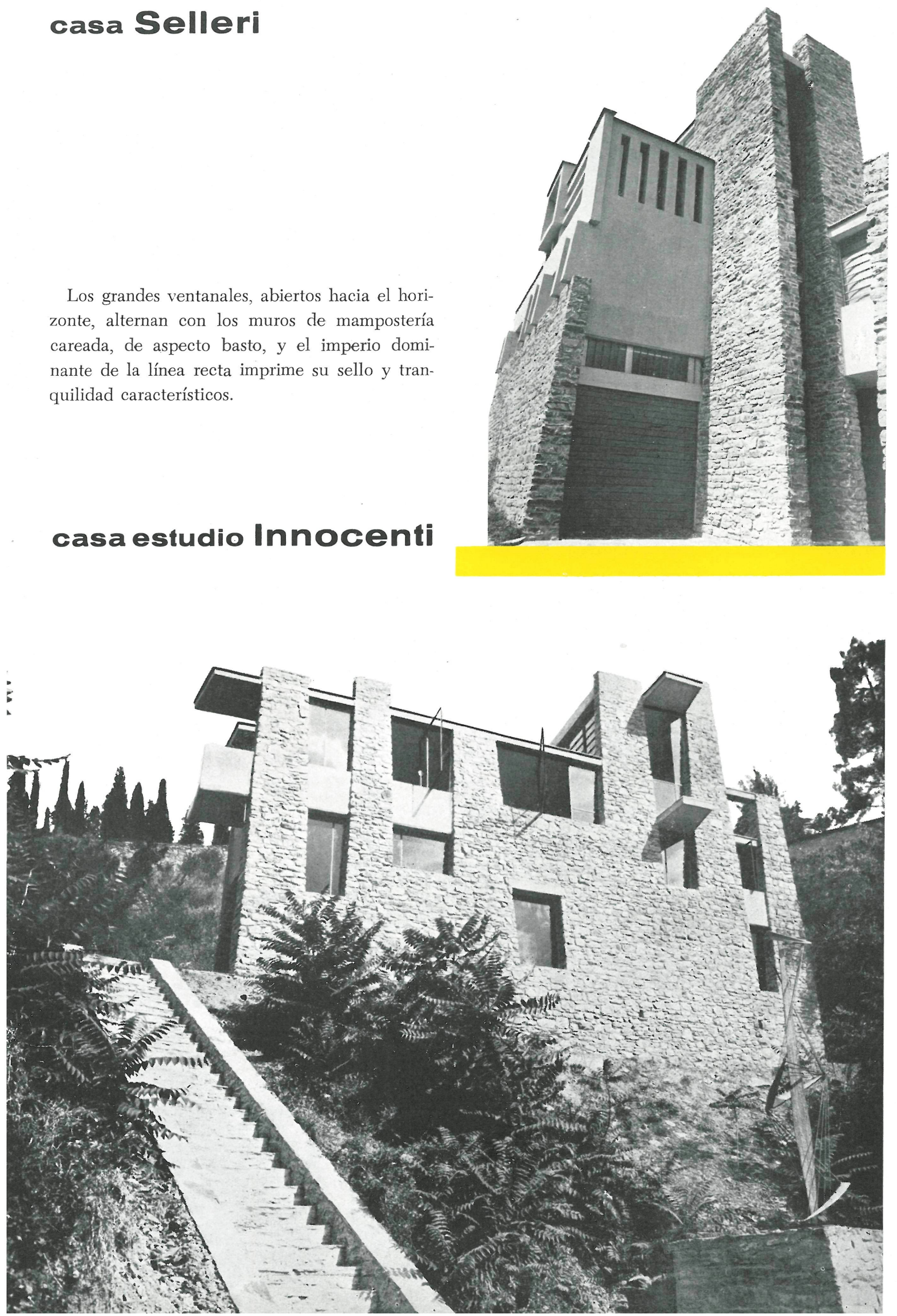

Fotos: 